\title{
Temporary display
}

\section{If you look on short-term employment as a way of window shopping, you could get a bargain.}

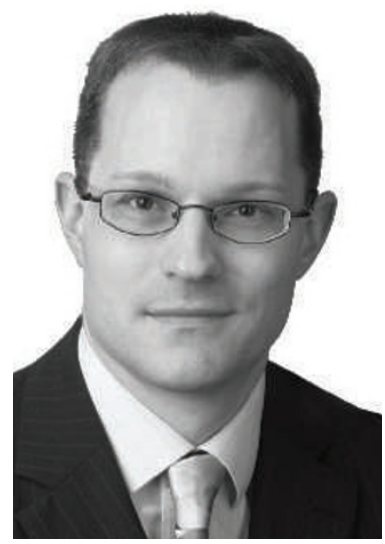

Martin Lang
SCENE: A pavement café in a bustling European capital. A forlorn German scientist stares into her coffee. An American friend arrives and sits down.

\section{AMERICAN}

Hey, what's up? You're looking pretty stressed.

\section{GERMAN}

I've lost my job. It was such a great position, too: full-time, supposedly secure. I'd been there years. So now I'm looking for something similar - but I'm getting nowhere. All I can find are short-term slots. I just can't imagine working for six months, and then having to look for another job, and then another - and maybe having to move to another city.

\section{American}

You make it sound like torture - but it's actually not a bad life. Sure, it might not always be convenient, but then, what is? Temping exposes you to a host of different companies and it helps you to learn new skills.

\section{GERMAN}

Hmm. You might be right - in theory. But I'd still rather have the stability of a permanent position. I want to stay put until I retire.

\section{American}

To be honest, those days are over. It just doesn't happen any more. If the choice is between staying unemployed and trying something different, why not give temping a try?

This brief encounter is fictional - but it reflects accurately the views I have heard from both sides of the Atlantic when it comes to short-term contracts. To some, the idea of sacrificing the alleged security of a 'permanent' position for the life of a temp is a wholly unappealing prospect. But such feelings need to be informed by a healthy dose of reality.
There is no point mourning a job market that has been undergoing dramatic change for several years. It's even less useful to stick your head in the sand and convince yourself that you'll soon get a permanent job if you are in a sector where there are few such opportunities. So if you're not tied down with family and financial commitments, why not make use of your freedom to exploit the temporary job market?

Both employers and employees are constantly reacting to changes caused by globalization, new technology and shifting scientific and political fortunes. Temporary employment is one reaction to these changes. It is accepted in most sectors as a way to keep staffing levels responsive to fluctuating needs. But to $\mathrm{PhD}$ scientists in some parts of the world, the idea of temporary employment can, as in our story, elicit a negative response.

The term 'temp' can also carry negative connotations. "We would never trust a temp in this responsible position," a drug company in Germany once said in a discussion about its staffing needs. What was it afraid of? Transfer of knowledge to someone who was just passing through? Didn't the company rely on its employees' skills and qualifications? And didn't it expect employees to be flexible and have a broad knowledge of different scientific fields? Or was the firm not prepared to pay adequate salaries for the appropriate skills?

In many countries, such as Britain or the United States, temporary employment in the scientific industry is far more common than on the European mainland. Although hiring a very qualified scientist on a temporary basis may mean higher shortterm labour costs, these arrangements are accepted by both employer and the employee.

Some trepidation about temporary employment is natural - particularly in cultures that value permanent jobs, and among people with financial commitments. But the philosophy behind such posts can make employers wary. What if they get stuck with someone whose skills are only useful for a certain period? What if the new person is simply not a 'good fit'? In many European countries, employees are protected from losing their jobs in such circumstances.

Temporary posts offer an alternative, with benefits to both the employee and the employer. For companies that are cautious about bringing in high-level staff permanently, it gives them an opportunity to see the scientists in action, before they make a more long-term commitment. In my experience, just over half of temping positions result in such offers.

For the employee, such positions offer more than just six months' salary. They provide an opportunity to gain new skills and to experience work in different organizations. Many firms offer placements in different parts of the world, thus allowing scientists their geographical preferences something that can be hard when seeking an academic position. In fact, scientists seeking temporary work may actually have more choice over location than those in long-term posts.

The biggest benefit to both sides, of course, occurs when the temp's skill set meshes with the long-term needs of the company and the temporary employee has the chance to become permanent. Both the company and the employee understand each other, eliminating fears from both sides about being 'a good fit' for each other. Temporary employment in the scientific industry allows scientists and companies to try each other on for size. 